\title{
Pedobarography Study Among Malay Population In The District Of Kuantan, Pahang: A Preliminary Report
}

Muhammad Haidar bin Nasuruddin ${ }^{1}$, Aminudin bin Che Ahmad ${ }^{1}$, Mohd Adham Syah bin Ayeop ${ }^{1}$, Nik Mohd. Fatmy Bin Nik Mohd. Najmi ${ }^{1}$

${ }^{1}$ Department of Orthopaedics, Traumatology and Rehabilitation, Kulliyyah of Medicine, International Islamic University Malaysia

Presenter: Muhammad Haidar bin Nasuruddin

Introduction: Plantar foot pressure has been widely used in managing foot-related disease in developed countries for the past 2 decades. However, in Malaysia, it is still at its infancy. Studies showed that the normal values are not affected by gender and body mass index (BMI), but vary between one race to another. Currently, to the best of author's review, there is no standard value available for Malaysian or Southeast Asia population. This study is designed to measure pressure values observed in the normal foot of Malay population in Kuantan and its difference between different gender and BMI. Materials and Methods: Measurements were taken from 184 healthy subjects, 79 males and 105 females. Age and BMI were identified. Plantar pressures were measured using Emed-q100 pedobarography platform device with its emed/E (Expert) software Results: The median plantar pressure was $480 \mathrm{kPa}$ (IQR 205). There was no significant difference between genders $(p=0.483)$ and BMI $(p=0.076)$ Conclusion: This result is not meant to represent the whole Malay population but rather to be used as an early reference for plantar pressure studies among Malay population. More studies are needed to more accurately describe the value of the population 